\title{
Intradiscal injection of monosodium iodoacetate induces intervertebral disc degeneration in an experimental rabbit model
}

\author{
Takao Sudo ${ }^{1 \dagger}$, Koji Akeda $^{{ }^{*}+}$ (D), Koki Kawaguchi ${ }^{1}$, Takahiro Hasegawa ${ }^{1}$, Junichi Yamada ${ }^{1}$, Nozomu Inoue $^{2}$, \\ Koichi Masuda ${ }^{3}$ and Akihiro Sudo?
}

\begin{abstract}
Background: Establishing an optimal animal model for intervertebral disc (IVD) degeneration is essential for developing new IVD therapies. The intra-articular injection of monosodium iodoacetate (MIA), which is commonly used in animal models of osteoarthritis, induces cartilage degeneration and progressive arthritis in a dose- and timedependent manner. The purpose of this study was to determine the effect of MIA injections into rabbit IVDs on the progression of IVD degeneration evaluated by radiographic, micro-computerized tomography (micro-CT), magnetic resonance imaging (MRI), and histological analyses.
\end{abstract}

Methods: In total, 24 New Zealand White (NZW) rabbits were used in this study. Under general anesthesia, lumbar discs from $L 1-L 2$ to $L 4-L 5$ had a posterolateral percutaneous injection of MIA in contrast agent (CA) (L1-L2: CA only; L2-L3: MIA 0.01 mg; L3-L4: 0.1 mg; L4-L5: 1.0 mg; L5-L6: non-injection (NI) control). Disc height was radiographically monitored biweekly until 12 weeks after injection. Six rabbits were sacrificed at 2, 4, 8, and 12 weeks post-injection and processed for micro-CT, MRI (T2-mapping), and histological analyses. Three-dimensional (3D) disc height in five anatomical zones was evaluated by 3D reconstruction of micro-CT data.

Results: Disc height of MIA-injected discs (L2-L3 to L4-L5) gradually decreased time-dependently $(P<0.0001)$. The disc height of MIA $0.01 \mathrm{mg}$-injected discs was significantly higher than those of MIA 0.1 and $1.0 \mathrm{mg}$-injected discs ( $P$ $<0.01$, respectively). 3D micro-CT analysis showed the dose- and time-dependent decrease of 3D disc height of MIAinjected discs predominantly in the posterior annulus fibrosus (AF) zone. MRI T2 values of MIA 0.1 and $1.0 \mathrm{mg}$-injected discs were significantly decreased compared to those of CA and/or NI controls $(P<0.05)$. Histological analyses showed progressive time- and dose-degenerative changes in the discs injected with MIA $(P<0.01)$. MIA induced cell death in the rabbit nucleus pulposus with a high percentage, while the percentage of cell clones was low.

Conclusions: The results of this study showed, for the first time, that the intradiscal injection of MIA induced degenerative changes of rabbit IVDs in a time- and dose-dependent manner. This study suggests that MIA injection into rabbit IVDs could be used as an animal model of IVD degeneration for developing future treatments.

Keywords: Intervertebral disc, Disc degeneration, Monosodium iodoacetate, $\mu \mathrm{CT}$, MRI, Histology, Rabbit, Animal model

\footnotetext{
*Correspondence: k_akeda@clin.medic.mie-u.ac.jp

†Takao Sudo and Koji Akeda contributed equally to this work.

1 Department of Orthopaedic Surgery, Mie University Graduate School of Medicine, 2-174 Edobashi, Tsu City, Mie 514-8507, Japan

Full list of author information is available at the end of the article
}

\section{Background}

Low back pain (LBP), a prevalent worldwide health problem afflicting patients ranging from children to the elderly, is a major cause of disability [1]. Clinically, original author(s) and the source, provide a link to the Creative Commons licence, and indicate if changes were made. The images or other third party material in this article are included in the article's Creative Commons licence, unless indicated otherwise in a credit line to the material. If material is not included in the article's Creative Commons licence and your intended use is not permitted by statutory regulation or exceeds the permitted use, you will need to obtain permission directly from the copyright holder. To view a copy of this licence, visit http://creativecommons.org/licenses/by/4.0/. The Creative Commons Public Domain Dedication waiver (http://creativeco mmons.org/publicdomain/zero/1.0/) applies to the data made available in this article, unless otherwise stated in a credit line to the data. 
intervertebral disc (IVD) degeneration is an important cause of pain in LBP patients [2,3]. The pathophysiology of human IVD degeneration is complex and multifactorial, and environmental and endogenous factors under genetic predisposition are considered to initiate the degenerative changes of human IVDs (see review in [4]).

It is important to establish an optimal animal model for IVD degeneration that mimics the biological process of human IVD degeneration in order to elucidate the pathological mechanisms of degenerative disc diseases and to develop novel treatments for them.

The IVD consists of the gelatinous nucleus pulposus (NP) surrounded by the annulus fibrosus (AF), a concentrically organized lamella structure of collagen fibers. The NP is rich in an extracellular matrix (ECM) that mainly contains the hydrophilic proteoglycan (PG) "aggrecan" and type II collagen [5]. The cells in human IVDs undergo a phenotypic change in the NP from notochordal cells to chondrocyte-like cells in childhood [6]. With increasing age or degeneration, there is an increase in cell proliferation (formation of cell clusters) and an increase in cell death [7]. These cellular changes are accompanied by biochemical changes in the ECM constituents, including a decrease in water and PG content that leads to tissue fibrosis in the NP [4].

Consequently, the number and extent of intervertebral clefts and tears are increased [8]. With the recent progress of image analysis technology, these biochemical and histological features of human IVD degeneration are now able to be evaluated by magnetic resonance imaging (MRI) $[9,10]$ and computed tomography (CT) images [11]. These cellular and biochemical changes also influence disc function and structure characterized by disc height narrowing $[12,13]$. Numerous animal models of IVD degeneration have been reported and have been compared regarding the histological, biochemical, and structural characteristics of human IVD degeneration [14].

Monosodium iodoacetate (MIA) is commonly used in animal models of osteoarthritis (OA) (see review in [15]). MIA inhibits glyceraldehyde-3-phosphate dehydrogenase activity in chondrocytes, resulting in disruption of glycolysis and eventual cell death [16] and apoptosis [17]. The intra-articular injection of MIA induces a reduction in the number of chondrocytes and morphological and histological changes of articular cartilage, similar to those changes in human osteoarthritis $(\mathrm{OA})[18,19]$. Udo et al. recently reported that MIA injection into rat knee joints induced cartilage degeneration and progressive arthritis in a dose- and time-dependent manner [20]. The injection of a low amount of MIA induced cartilage degeneration without bone destruction, as found in the pathology of an early stage of OA. By contrast, a high dose of MIA showed a severe degradation of cartilage with the destruction of subchondral bone [20].

IVDs and articular cartilage share remarkably similar anatomical composition, biochemical features, and molecular processes of matrix degeneration. Suh et al. [21] recently investigated the effect of MIA injection into rat IVDs, mainly on behavior analysis during 6 weeks post-injection, and showed that the intradiscal injection of MIA $(4.0 \mathrm{mg})$ affected pain behavior with severe degenerative changes of rat IVDs. Rapid and severe degeneration with complete cell loss is not optimum to study the effect of biologics. In addition, a large animal model, such as rabbits, is suitable to control doses of materials to be injected without backflow from a needle hole after injection. It is essential to retain some functional cells to investigate cell-mediated tissue regeneration in a preclinical model.

Therefore, we hypothesized that (i) the intradiscal injection of MIA induces the degeneration of rabbit IVDs in a dose- and time-dependent manner, and (ii) the proper dose of MIA can be used in an animal model to study IVD degeneration for preclinical studies of IVD therapy.

The purpose of this study was to determine the effect of MIA injection into rabbit IVDs on the progression of IVD degeneration evaluated by radiographic, microcomputed tomography (micro-CT), magnetic resonance imaging (MRI), and histological analyses, and to establish a new rabbit IVD degeneration model.

\section{Methods \\ Procedure}

This study was conducted in strict accordance with recommendations in the Guide for the Care and Use of Laboratory Animals of the National Institutes of Health. The protocol of this study was approved by the Institutional Animal Care and Use Committee. Twenty-four New Zealand white rabbits (female), ranging from 2.9 to $3.4 \mathrm{~kg}$ in body weight (SLC, Hamamatsu, Japan), were used in this study. Rabbits were housed in separate cages under standard conditions with a light-dark cycle (12 h-12 h) and dry-bulb room temperature at $22-24^{\circ}$ and provided ad libitum access to tap water and food pellets daily. Rabbits were anesthetized by an intramuscular injection of ketamine hydrochloride (25 mg/kg; Ketalar ${ }^{\circledR}$; Daiichi Sankyo, Tokyo, Japan) mixed with xylazine $(5 \mathrm{mg} / \mathrm{kg}$; Selactar $^{\circledR}$, Bayer, Tokyo, Japan). Lateral plain radiographs were obtained to determine baseline IVD height values before the treatment. Under single fluoroscopy (C-arm image intensifier, Philips Med System), rabbits were then placed into a lateral prone position, and a nonionic, isotonic contrast agent (CA) (Iotrolan 240, Bayer Global, Leverkusen, Germany) or MIA (305-53-3, Sigma-Aldrich, 
St. Louis, MO, USA) was injected into the rabbit IVDs from the posterolateral to the center percutaneously using micro syringes with a $31 \mathrm{G}$ needle (Ito Corporation, Fuji, Japan). L1-L2 discs received $10 \mu \mathrm{l}$ of CA only, L2-L3 discs received MIA $0.01 \mathrm{mg}$ (in $10 \mu \mathrm{l} \mathrm{CA}$ ), L3-L4 MIA $0.1 \mathrm{mg}$ (in $10 \mu \mathrm{l} \mathrm{CA}$ ), and L4-L5 MIA $1.0 \mathrm{mg}$ (in $10 \mu \mathrm{l} \mathrm{CA}$ ). L5-L6 discs were used as non-injection (NI) controls (Fig. 1). The use of the lumbar spine lowest levels (L6-L7) was avoided to eliminate possible influences of the lumbosacral junction.

Six rabbits were euthanized at 2, 4, 8, and 12 weeks post-injection, and the spinal columns (L1 to L6 vertebra) were harvested. At each time point, three spinal columns were processed for micro-computed tomography (CT) and another three for magnetic resonance imaging (MRI), followed by histological analysis.

\section{Radiographic analysis of disc height}

To assess the height of each disc, lateral radiographs of the lumbar segment were taken just before injection and at 2-week intervals after that until the animals were euthanized. Under general anesthesia, a lateral lumbar radiograph was taken using fluoroscopy. A $10-\mathrm{mm}$ metal wire was placed at the height of the rabbit spine in the lateral recumbent position as a marker for calibration. All radiographic images were independently analyzed using an image analysis software, ImageJ (US National Institutes of Health, Bethesda, MD, USA), by an orthopedic researcher blinded to the treatment groups. The IVD height was measured using the method of Masuda et al. [22], with a modification. Anterior disc height $(\mathrm{Ha})$, middle disc height $(\mathrm{Hm})$, and posterior disc height $(\mathrm{Hp})$ were measured and calibrated (Fig. 2). Disc height (DH) was calculated as follows: (Ha+Hm+Hp) / 3 (Fig. 2). The disc height index (DHI) was defined as: DH (of L1-L2, L2-L3, L3-L4, or L4-L5 discs) / DH of L5-L6 disc (NI control). Change in DHI was expressed as percentage DHI (\%DHI) and normalized to the measured baseline DHI: \% DHI = (post-injection DHI/baseline DHI) $\times 100$.

\section{Micro-CT analysis}

Lumbar spinal columns with surrounding soft tissues harvested at each time point $(n=3)$ were CT-scanned in an X-ray micro-CT scanner (Rigaku, RmCT, Tokyo,

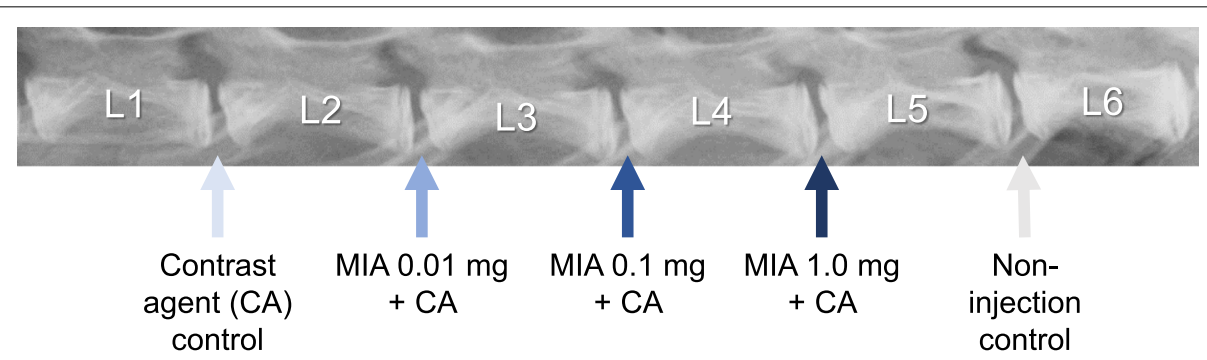

Fig. 1 Schema of monosodium iodoacetate (MIA) injection into rabbit intervertebral discs (IVDs). The contrast agent (CA) or MIA in CA was injected into rabbit IVDs. Each disc had a posterolateral percutaneous injection of CA or MIA in $10 \mu \mathrm{l}$ of CA with a 31G needle using a micro syringe. L5-L6 had no operation and was used as a non-injection (NI) control

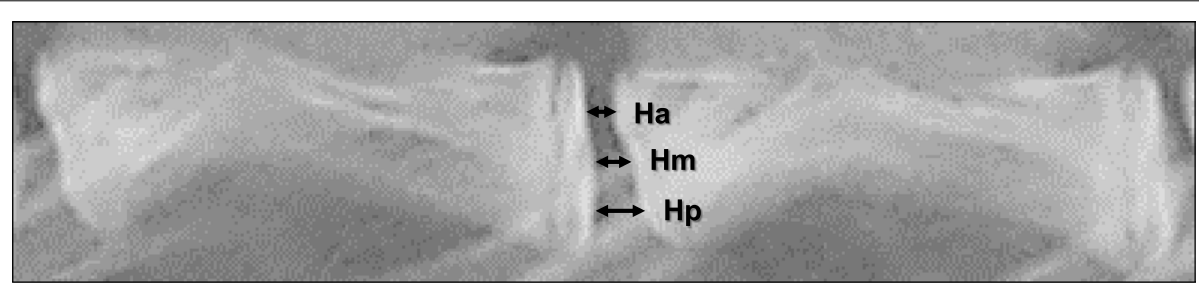

\section{Disc height $(\mathrm{DH})=(\mathrm{Ha}+\mathrm{Hm}+\mathrm{Hp}) / 3$}

$$
\begin{aligned}
& \mathrm{DHI}=\mathrm{DH} \text { (of L1-L2 to L4-L5 discs) / DH of L5-L6 } \\
& \% \mathrm{DHI}=\text { post-injected DHI / baseline } \mathrm{DHI} \times 100
\end{aligned}
$$

Fig. 2 Radiographic measurement of disc height. Anterior disc height $(\mathrm{Ha})$, middle disc height $(\mathrm{Hm})$, and posterior disc height $(\mathrm{Hp})$ were measured and calibrated. Disc height $(\mathrm{DH})$ was calculated as $(\mathrm{Ha}+\mathrm{Hm}+\mathrm{Hp})$ /3. The disc height index (DHI) was defined as: $\mathrm{DH}(\mathrm{L} 1-\mathrm{L} 2, \mathrm{~L} 2-\mathrm{L} 3, \mathrm{~L} 3-\mathrm{L} 4, \mathrm{or} \mathrm{L} 4-\mathrm{L} 5$ disc) / DH of L5-L6 disc (non-injection (NI) control). Change in DHI was expressed as percentage DHI (\%DHI) and normalized to the measured baseline $\mathrm{DHI}: \% \mathrm{DHI}=($ post-injection $\mathrm{DHI} /$ baseline $\mathrm{DHI}) \times 100$ 
Japan). The X-ray source operates at $75 \mathrm{kV}$ and $100 \mu \mathrm{A}$, scan time $17 \mathrm{~s}$, and voxel size $24 \mu \mathrm{m}$. Digital Imaging and Communications in Medicine (DICOM) data were reconstructed to three-dimensional (3D) images of vertebral body-disc-vertebral body units in Mimics 17.0 (Mimics, Materialise Inc., Leuven, Belgium). Then, isolation of the endplates was completed in 3-matics (Materialise Inc.), and endplates were exported as point cloud data (Fig. 3). For measuring the 3D-disc height (3D-DH), the least distances from one point in the point cloud model of the inferior endplate to the points in the superior endplate were calculated using a custom-written Visual $\mathrm{C}++$ program $[23,24]$. The average of least distance was calculated by repeating this procedure for all points in the inferior endplate, and then the averaged distance was defined as the 3D-DH of the whole disc. Next, the IVD was separated into five anatomical areas (posterior, left-lateral [L-lateral], right-lateral [R-lateral], anterior, and nucleus pulposus $[\mathrm{NP}]$ ) that represent the $\mathrm{AF}$ and $\mathrm{NP}$ footprints ideally. The 3D-DH of each area was measured as described above [23, 24].

In order to evaluate the differences of 3D-DH among the five zones, the percentage of 3D-DH of all five zones against those of L5-L6 discs were calculated as 3D-DHI: (3D-DH of each disc) / (3D-DH of L5-L6) $\times 100(\%)$. 3D-DHI was evaluated in all the discs injected with CA or MIA after 2, 4, 8, and 12 weeks post-injection. All five zones were divided into four groups depending on the degree of 3D-DHI as follows: 3D-DHI $<70 \%, 70 \% \leqq 3 \mathrm{D}-$ DHI $<80 \%, 80 \% \leqq 3 \mathrm{D}-\mathrm{DHI}<90 \%, 90 \% \leqq 3 \mathrm{D}-\mathrm{DHI}$.

\section{MRI analysis}

L1 to L6 vertebrae with surrounding soft tissues were isolated and wrapped by plastic cling film to prevent dehydration and kept in an ice box until subjected to quantitative transverse relaxation time (T2) MRI analysis as previously reported [25]. MRI was performed using a 3.0-Tesla imager (Achieva 3.0T; Philips, Amsterdam, The Netherlands) with a 3-inch birdcage extremity coil (Philips). The room temperature was kept at $24{ }^{\circ} \mathrm{C}$ during the MRI scan. Quantitative T2 mapping was performed by using a multi-echo spin-echo sequence in the sagittal plane. Scanning parameters were the following: timeto-repeat $(\mathrm{TR})=2500 \mathrm{~ms}$; time-to-echo $(\mathrm{TE})=20,40$, $400 \mathrm{~ms}(20 \mathrm{TEs}) \mathrm{ms}$; field of view $=10 \mathrm{~cm}$; slice thickness $=3 \mathrm{~mm}$; image matrix $=560 \times 560$; and number of excitations $=1$. The total scanning time per sample was 9 min $22 \mathrm{~s}$. For creating color-coded T2 maps, MRI images at multiple TE were imported into the medical image processing software (EV Insite, PSP corporation, Tokyo, Japan) with a T2 mapping plug-in. Mean signal intensities were determined in the regions of interest (ROI) framing the outer border of the AF on T2-weighted images taken at TE of $100 \mathrm{~ms}$ [25].

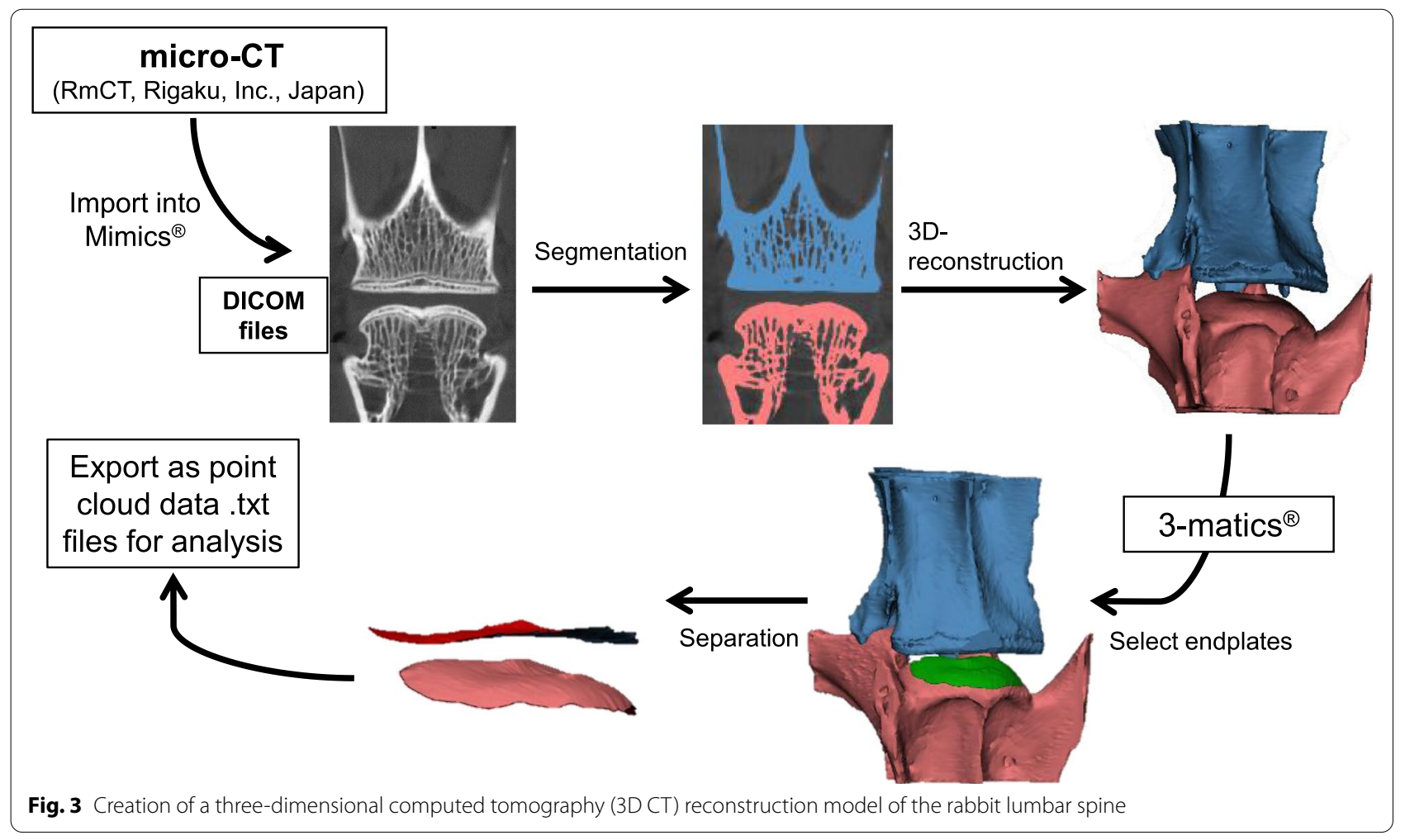




\section{Histological analysis}

Following micro-CT and MRI assessment, the experimental IVDs were excised from the vertebral bodydisc-vertebral body unit, and each IVD was fixed in $4 \%$ paraformaldehyde for 14 days at $4{ }^{\circ} \mathrm{C}$ and then permeated in HCL-based decalcified reagent (K-CX, Falma, Inc., Tokyo, Japan), embedded in paraffin, sectioned, and assessed by conventional histology. Mid-sagittal sections $(5 \mu \mathrm{m})$ of each IVD were stained with hematoxylin and eosin, and safranin-O and fast green. Blinded to the experiment, an observer analyzed the histological sections and graded them using the recently established standardized histopathology scoring system of rabbit IVD degeneration [26-28].

\section{Cell counting of "survived" cells in the rabbit nucleus pulposus}

Cells in the NP area with clear hematoxylin-stained nuclei within the eosin-stained cytoplasm were defined as "survived" cells (living cells) [29]. Cells with nuclei with an abnormal appearance were defined as "dead cells." The number of "survived" cells was quantified by manually counting from three fields of view in the NP area (anterior, center, and posterior) of microscopic images per sample at $\times 200$ magnification.

\section{Statistical analysis}

Differences in \%DHI, 3D-DHI, and MRI T2-values were assessed for statistical significance by two-way repeatedmeasures analysis of variance (ANOVA) followed by the Bonferroni or Tukey's Honest Significant Difference
(HSD) post hoc test. Histological grading scores were assessed by the Kruskal-Wallis test for inter-group comparisons and the Friedman test for temporal changes. All data are expressed as mean \pm standard deviation (SD). All the statistical analyses were performed using IBM Statistical Package for Social Sciences Software (SPSS) Statistics (IBM Japan, Tokyo). The accepted level of significance was $P<0.05$.

\section{Results}

\section{Change in radiographic disc height}

The mean \%DHI of discs injected with MIA (L2-L3, L3-L4, and L4-L5) decreased time-dependently $(P<$ $0.01)$ and was significantly lower compared to that of the CA control (L1-L2) $(P<0.01$, respectively) (Fig. 4). The \%DHI of MIA $0.01 \mathrm{mg}$-injected discs (L2-L3) was significantly higher than that of MIA $0.1 \mathrm{mg}$-injected discs (L3-L4) and MIA 1.0 mg-injected discs (L4-L5) $(P<$ 0.01 , respectively); however, no significant difference was identified between MIA 0.1 mg-injected discs (L3-L4) and MIA 1.0 mg-injected discs (L4-L5) (Fig. 4).

The intradiscal injection of MIA $0.01 \mathrm{mg}$ induced a significant decrease of \%DHI to approximately $87 \%$ of baseline at 4 weeks post-injection; this continued to decrease to approximately $81 \%$ at 12 weeks post-injection. The \%DHI of MIA $0.1 \mathrm{mg}$ - and $1.0 \mathrm{mg}$-injected discs significantly decreased to approximately $75 \%$ and $66 \%$ of baseline at 4 weeks post-injection, and approximately $61 \%$ and $56 \%$ at 12 weeks post-injection. The timepoint analysis showed that \%DHI of MIA 0.01 mg-injected discs was significantly higher than that of MIA 0.1 mg-injected

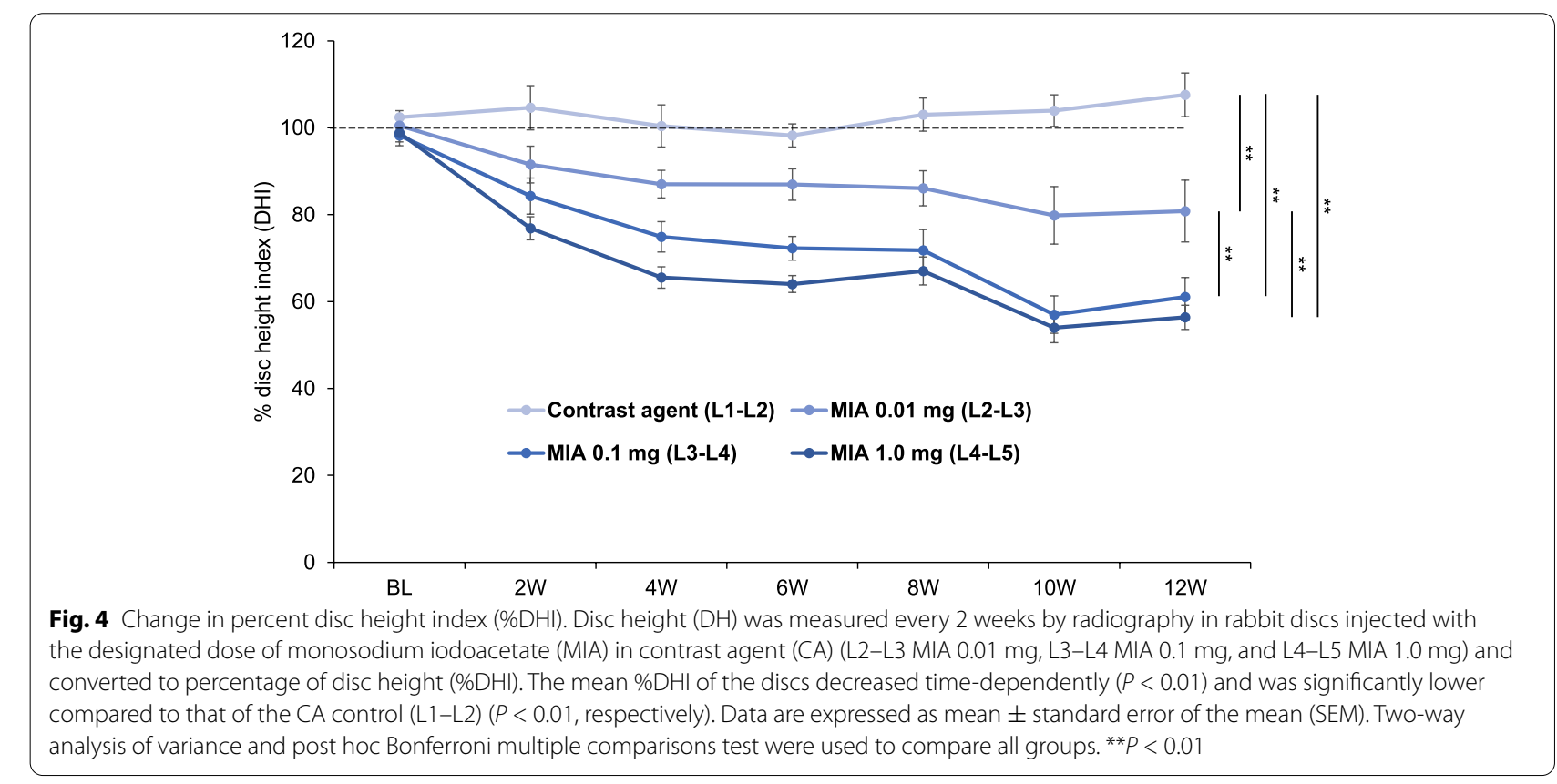


discs at 6 weeks $(P<0.01)$ and 10 weeks $(P<0.05)$ postinjection and MIA $1.0 \mathrm{mg}$-injected discs at 4 weeks $(P<$ $0.01), 6$ weeks $(P<0.01), 8$ weeks $(P<0.05), 10$ weeks $(P$ $<0.01)$, and 12 weeks $(P<0.05)$ post-injection. On the other hand, there were no significant differences in \%DHI between the discs injected with MIA $0.1 \mathrm{mg}$ and $1.0 \mathrm{mg}$ from baseline to 12 weeks post-injection.

\section{Change in three-dimensional (3D) disc height}

In the anatomical zone analysis, the 3D-DHI was calculated at each disc level and is shown as a color map (Fig. 5). In the CA control (L1-L2) discs, the 3D-DHI of all five zones at each timepoint was more than $90 \%$, except for the posterior zone at week 2 (Fig. 5). In MIA 0.01 mg-injected discs (L2-L3), the area with $3 \mathrm{D}-\mathrm{DHI}<90 \%$ was mainly identified at posterior and NP zones, but not at lateral (right and left) zones. In the MIA $0.1 \mathrm{mg}$-injected discs (L3-L4), the 3D-DHI of posterior zones time-dependently decreased from 2 weeks $(68.8$ $\%)$ to 12 weeks (38.2\%) after injection. A time-dependent decrease of 3D-DHI from $87.4 \%$ at 2 weeks to $61.3 \%$ at 12 weeks was found at the NP zone. The area with $3 \mathrm{D}-\mathrm{DHI}<90 \%$ was also identified at anterior and lateral zones 8 and 12 weeks after the injection. In the MIA 1.0 mg-injected discs (L4-L5), the 3D-DHI of all five zones was less than $90 \%$ from week 2 to week 12 . Notably, the
3D-DHI of posterior zones decreased from $56.4 \%$ at week 2 to $41.7 \%$ at week 12 .

\section{MRI assessment}

Representative sagittal images of color-coded T2 maps show a different degree of signal intensity of the NP, depending on disc level and timepoint (Fig. 6). Higher T2 values, as indicated by red pixels, were uniformly observed in the NP of CA (L1-L2) and NI control (L5L6) discs throughout the experimental period. However, red pixels, replaced by orange or yellow pixels, were identified in the NP of MIA $0.01 \mathrm{mg}$ - or $0.1 \mathrm{mg}$-injected discs at 8 and 12 weeks post-injection. A significant loss of red pixels, replaced by blue to black pixels, was found in the discs injected with $1.0 \mathrm{mg}$ of MIA.

Two-way repeated-measures ANOVA showed that the $\mathrm{T} 2$ value of the whole disc time-dependently decreased $(P<0.01)$ and differed significantly depending on the disc level during the observation period $(P<0.01)$ (Fig. 7). T2 values of CA control (L1-L2) discs showed no significant changes compared to NI controls (L5-L6) discs. The intradiscal injection of MIA $1.0 \mathrm{mg}$ (L4-L5 discs) significantly decreased T2 values compared to those of CA control (L1-L2) discs $(P<0.01)$ (Fig. 7). Timepoint analysis showed significant differences in T2 values among the groups at week 8 post-injection $(P<0.01)$. The mean

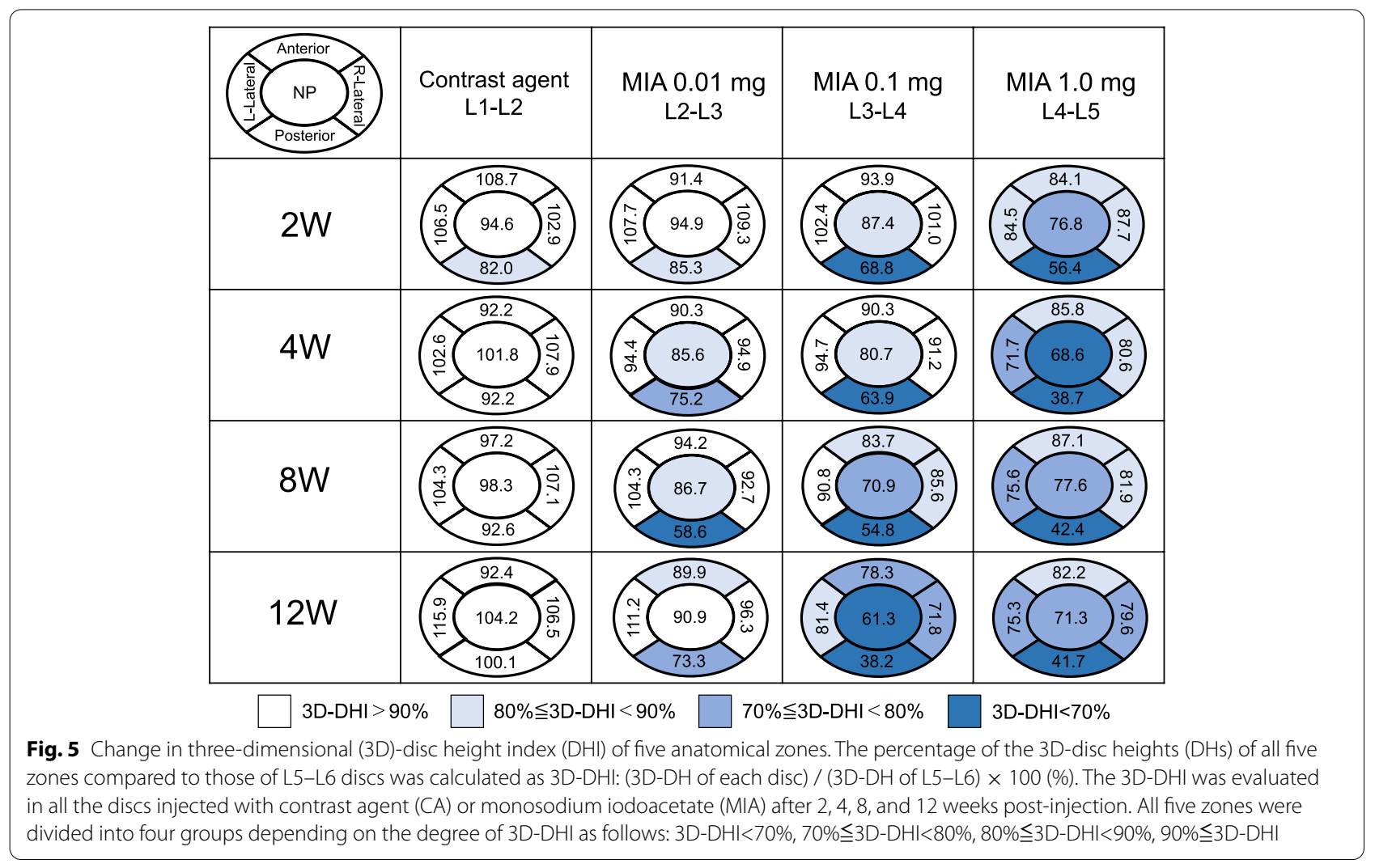




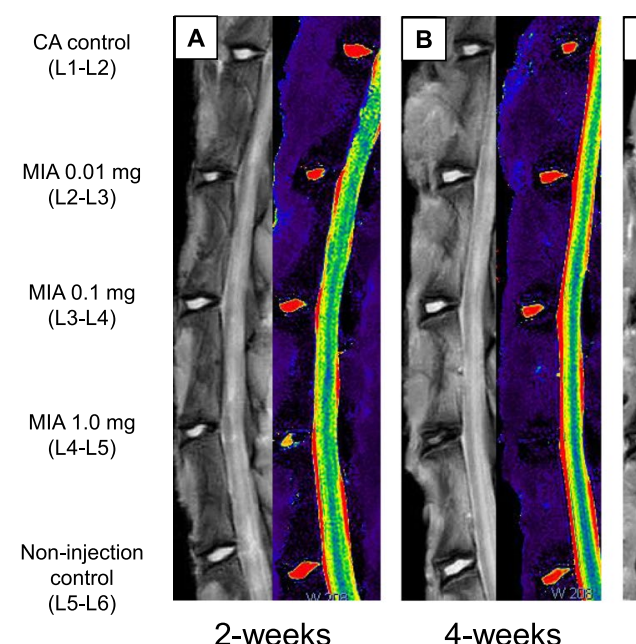

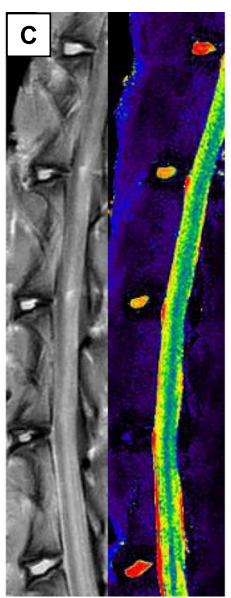

8-weeks

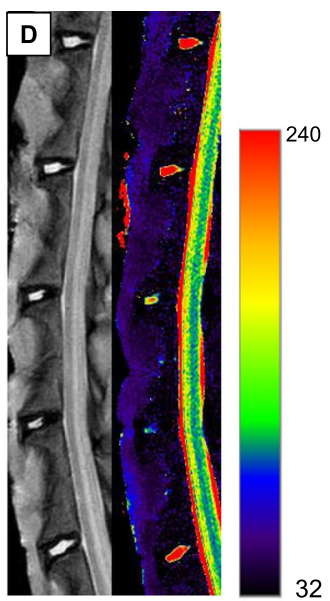

12-weeks 2-value

(ms)

Fig. 6 Representative sagittal magnetic resonance T2-weighted images (left panels) and T2 maps (right panels) of rabbit lumbar spines. A 2 weeks, B 4 weeks, C 8 weeks, and D 12 weeks after the injection of contrast agent (CA) and/or monosodium iodoacetate (MIA)

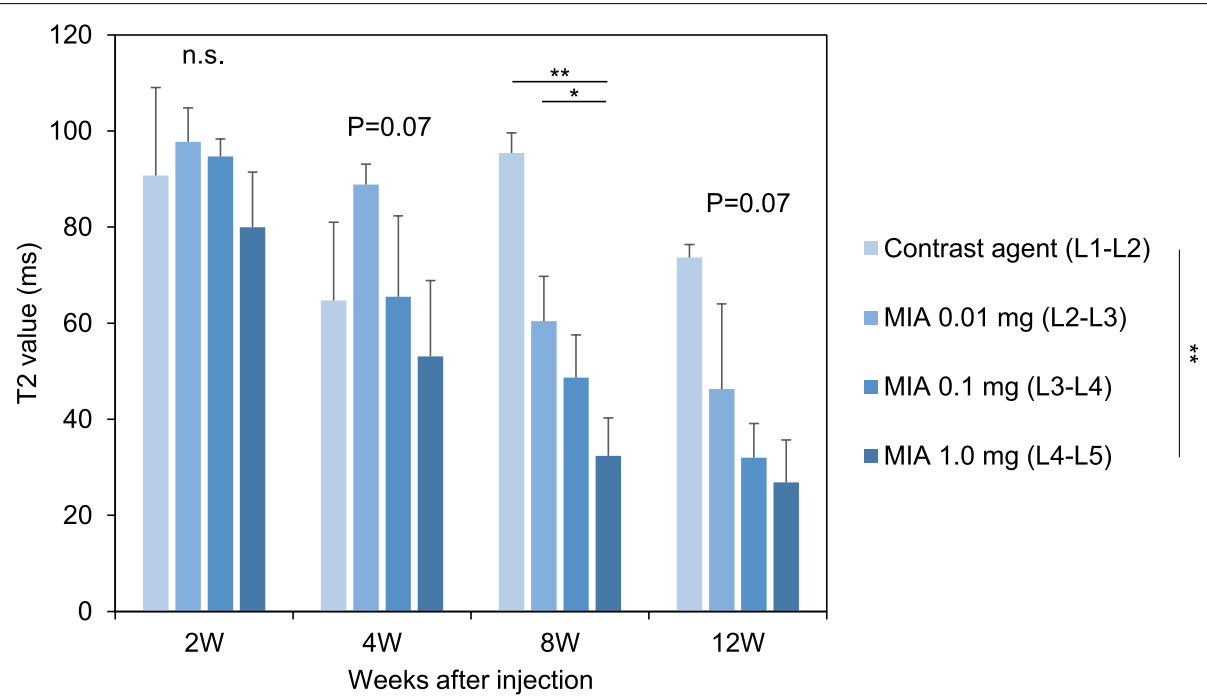

Fig. 7 Changes in T2 values of rabbit intervertebral discs (IVDs). Data are expressed as mean \pm standard error of the mean (SEM). Two-way analysis of variance and post hoc Bonferroni multiple comparisons test were used to compare all groups. ${ }^{*} P<0.05,{ }^{* *} P<0.01$

T2 value of MIA 1.0 mg-injected discs (L4-L5) was significantly lower than that of MIA $0.01 \mathrm{mg}$-injected discs (L2-L3) and CA control discs (MIA 0.01: $P<0.05$, CA: $P<0.01$ ) (Fig. 7). A similar trend of T2 values of MIAinjected discs was identified at 4 and 12 weeks postinjection; however, it did not reach statistical significance among groups ( 4 weeks: $P=0.07 ; 12$ weeks: $P=0.07$ ).

\section{Histological assessment}

Representative histology with Safranin-O staining at 4 and 12 weeks post-injection is shown in Figs. 8 and 9. At
4 weeks post-injection, the CA (Fig. 8A) and NI control (Fig. 8E) discs showed a normal histological appearance of rabbit IVDs, displaying an intact AF with a regular pattern of fibrocartilage lamellas with a well-defined border between the AF and NP (Fig. 8K, O). The NP consisted of numerous NP (vacuolated) cells within a fine cotton-like ECM (Fig. 8F, J). The intradiscal injection of MIA induced significant changes in histological appearance, especially in the NP at 4 weeks post-injection. MIA $0.01 \mathrm{mg}$ or 0.1 mg induced a slight to a moderate decrease of NP cells with slight condensation of the ECM (Fig. 8G, H). MIA 


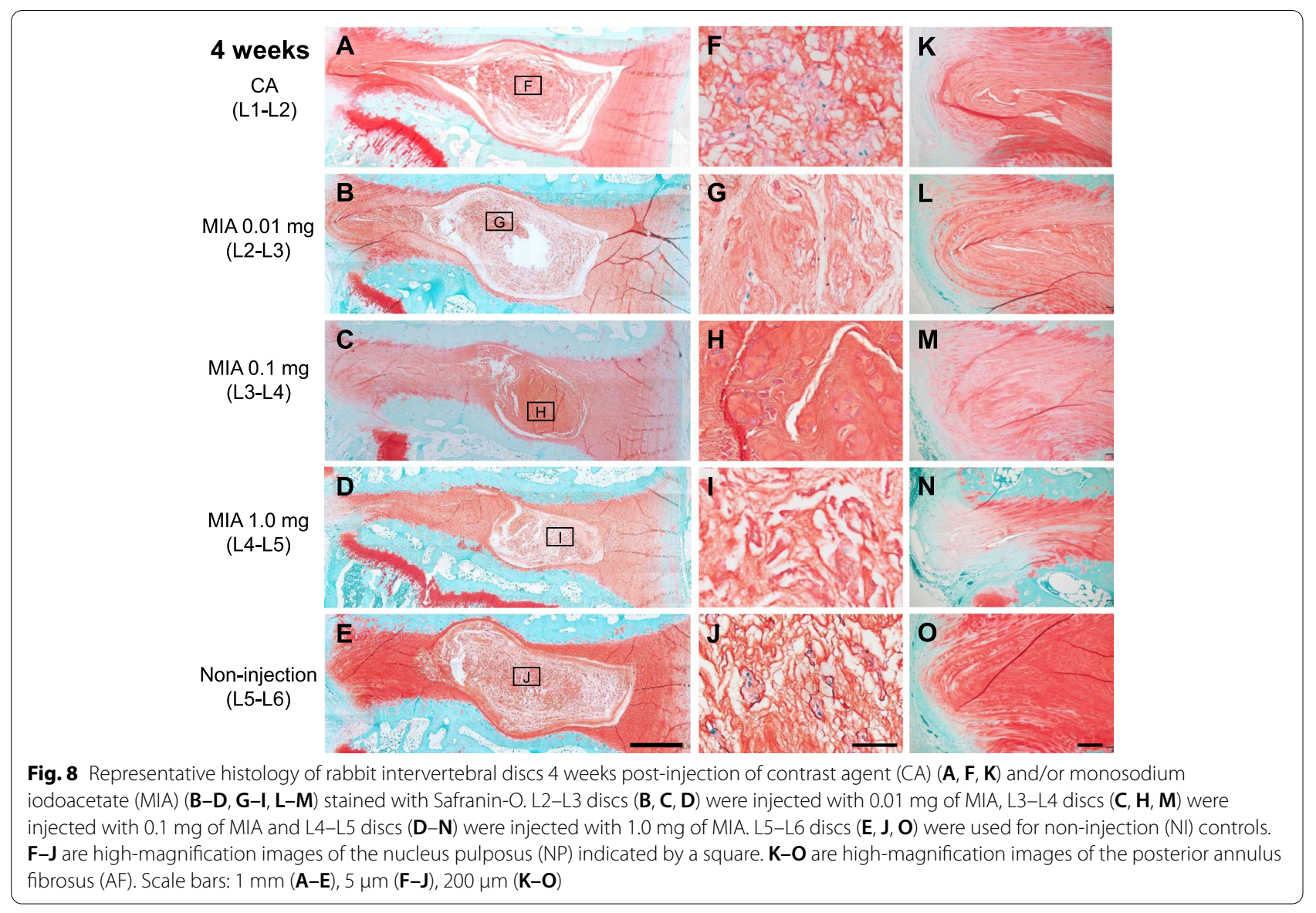

$1.0 \mathrm{mg}$ induced a severe decrease of NP cells with moderate condensation of the ECM (Fig. 8I). MIA $1.0 \mathrm{mg}$ also affected the histology of the posterior AF with partial ruptures and a serpentine pattern of fibers (Fig. $8 \mathrm{~N}$ ); this was not found in the anterior AF.

At 12 weeks post-injection, the progression in histological changes induced by MIA was observed in both NP and AF tissues (Fig. 9). MIA $0.01 \mathrm{mg}$ induced a moderate decrease of NP cells with local condensation of the ECM (Fig. 9G); AF fibers in posterior AF tissues were partially ruptured (Fig. 9L). MIA $0.1 \mathrm{mg}$ and $1.0 \mathrm{mg}$ induced a collapse of the NP tissue, with a significant decrease of NP cells and severe condensation of the ECM (Fig. 9H, I). Wavy fibrocartilage lamellas of the posterior AF with severely ruptured fibers were observed (Fig. 9M, N).

The intradiscal injection of MIA significantly affected the total histological score of rabbit disc degeneration [27] throughout the experimental period (weeks 2, 4, 8, and 12: all $P<0.01$ ) (Fig. 10A). There were no significant differences on total histological scores between the CA and NI controls.

The total histological scores of MIA 0.1 mg-injected discs were significantly higher than those in the CA control discs at week $12(P<0.01)$ (Fig. 10A). The intradiscal injection of MIA $1.0 \mathrm{mg}$ significantly increased the total histological scores compared to those of the CA control discs (week 2: $P<0.05$, week 4 to $12: P<0.01$, Fig. 10A). Histological grading scores of each of the seven categories, including the NP shape (Fig. 10B), NP area (Fig. 10C), NP matrix (Fig. 10D), NP cellularity (Fig. 10E), AF/NP border (Fig. 10F), AF (Fig. 10G), and endplate (EP) (Fig. 10H), are separately shown in Fig. 10.

\section{Cellular changes in nucleus pulpous cells}

Cellular changes in the NP cells of MIA 1.0 mg-injected discs are representatively shown in Fig. 11(A-D). Many NP cells with strong hematoxylin-stained nuclei in the eosin-stained cytoplasm were found 2 weeks post-injection (Fig. 11A). However, at 4 weeks post-injection, a substantial number of NP cells with weak hematoxylinstained nuclei (Fig. 11B), flattening of nuclei (Fig. 11C), and disintegration of nuclei (Fig. 11D) were detected.

At 12 weeks post-injection, the number of surviving cells in the MIA $0.01 \mathrm{mg}$-injected discs decreased to $40.6 \%$ of those in CA control discs, that of MIA 0.1 mg-injected discs was decreased to $19.1 \%$ of those in 

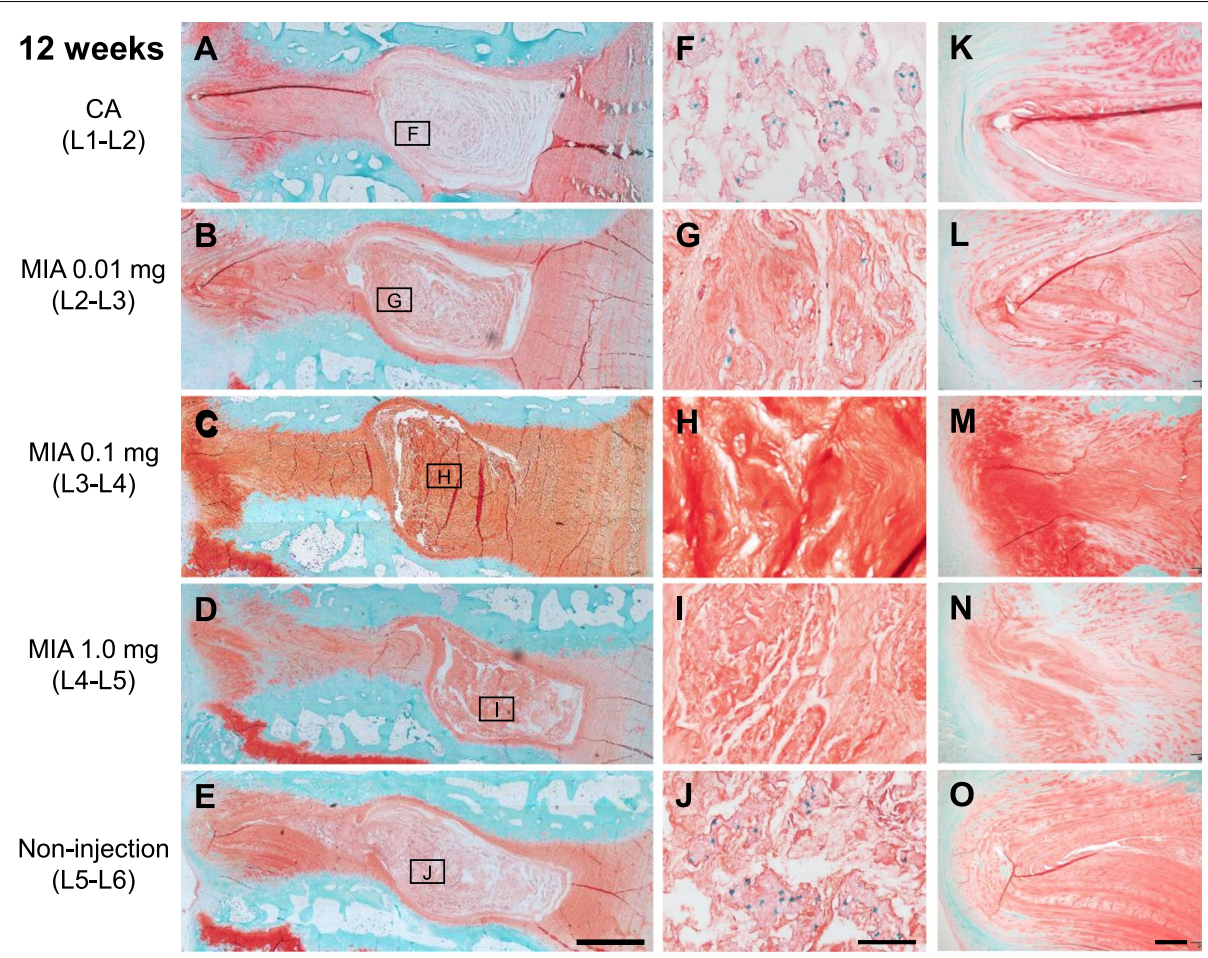

Fig. 9 Representative histology of rabbit intervertebral discs 12 weeks post-injection of contrast agent (CA) (A, F, K) and/or monosodium iodoacetate (MIA) (B-D, G-I, L-M) stained with Safranin-O. L2-L3 discs (B, C, D) were injected with $0.01 \mathrm{mg}$ of MIA, L3-L4 discs (C, H, M) were injected with $0.1 \mathrm{mg}$ of MIA and L4-L5 discs (D-N) were injected with $1.0 \mathrm{mg}$ of MIA. L5-L6 discs (E, J, O) were used for non-injection (NI) controls. $\mathbf{F}-\mathbf{J}$ are high-magnification images of the nucleus pulposus (NP) indicated by a square. $\mathbf{K}-\mathbf{O}$ are high-magnification images of the posterior annulus fibrosus (AF). Scale bars: $1 \mathrm{~mm}(\mathbf{A}-\mathbf{E}), 5 \mu \mathrm{m}(\mathbf{F}-\mathbf{J}), 200 \mu \mathrm{m}(\mathbf{K}-\mathbf{O})$

CA control discs, and that of MIA 1.0 mg-injected discs was decreased to $2.5 \%$ of those in CA control discs.

On the other hand, cell clones in NP tissues (Fig. 11E) were observed mainly in MIA 0.01 mg-injected discs (L2-L3) and MIA 0.1 mg-injected discs (L3-L4). In MIA 0.01 mg-injected discs, cluster formation was observed in $33.3 \%(2 / 6)$ of discs at 2 and 4 weeks, and $50 \%(3 / 6)$ of discs at 12 weeks. Cell clusters in the NP were also found in $33.3 \%(2 / 6)$ of MIA $0.1 \mathrm{mg}$-injected discs at 4 weeks post-injection and $33.3 \%(2 / 6)$ at 12 weeks post-injection. No cell clones were detected in discs injected with MIA $1.0 \mathrm{mg}$.

\section{Correlation between MRI T2 values and histological score}

MRI T2 values negatively correlated with the total histological score $(r=-0.83, P<0.01)$. The subclass analysis showed that MRI T2 values significantly correlated with NP shape $(r=-0.66, P<0.01)$, NP area $(r=-0.75, P<0.01)$, NP matrix $(r=-0.81, P<0.01)$, NP cellularity $(r=-0.67, P<0.01)$, AF/NP border $(r=$ $-0.78, P<0.01)$, AF $(r=-0.80, P<0.01)$, and EP $(r=$ $-0.32, P<0.01)$.

\section{Discussion}

For the first time, we have evaluated radiological and histological changes of rabbit IVDs after an intradiscal injection of MIA. This study showed that disc height, especially that of the posterior AF zone, time- and dose-dependently decreased, and MRI analysis showed a tendency for decreased T2 values in a time- and dose-dependent manner. Our results also showed that histological grading scores exacerbated time- and dosedependently after the injection of MIA. Importantly, we found that MIA induced a high percentage of cell death in the NP region.

Clinically, disc height narrowing on lumbar radiographs is a standard indicator for IVD degeneration [12]. To evaluate disc height, the ratio of disc height to that of the vertebral body, defined as "disc height index," has been used [22]. In this study, the actual value of disc height was directly measured by calibrating with a $10-\mathrm{mm}$ metal wire. Our results showed that no significant differences in disc height change against baseline, as represented by "percent disc height (\%DH)," between the CA control (L1-L2) and NI control (L5-L6) discs were found throughout the experimental period. This suggests 

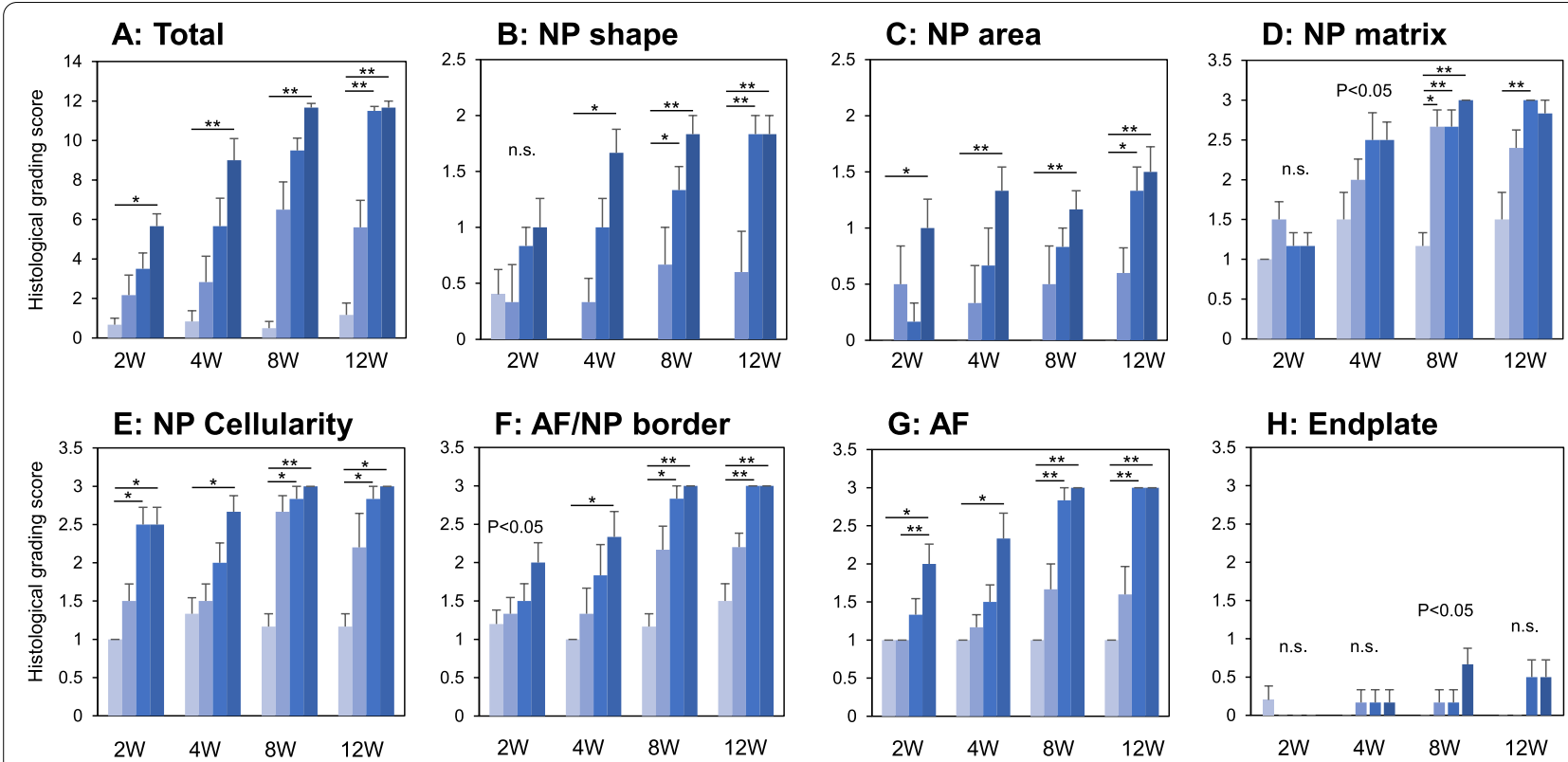

Contrast agent (L1-L2) _ MIA $0.01 \mathrm{mg}(\mathrm{L} 2-\mathrm{L} 3)$

MIA $0.1 \mathrm{mg}($ L3-L4)

MIA $1.0 \mathrm{mg}($ L4-L5)

Fig. 10 Histological grading scores. In rabbit intervertebral discs (IVDs) injected with contrast agent (CA) and/or monosodium iodoacetate (MIA) at 2, 4, 8, and 12 weeks post-injection, histological grading scores were evaluated using the standardized histopathology scoring system of rabbit IVD degeneration [26-28] for the total of seven categories: A total of seven categories, B nucleus pulposus (NP) shape, C NP area, D NP matrix, E NP cellularity, $\mathbf{F}$ border between the annulus fibrosus (AF) and NP, $\mathbf{G}$ AF, and $\mathbf{H}$ endplate. Data are expressed as mean \pm standard error of the mean (SEM). The Kruskal-Wallis test was used to compare all groups. ${ }^{*} P<0.05,{ }^{* *} P<0.01$

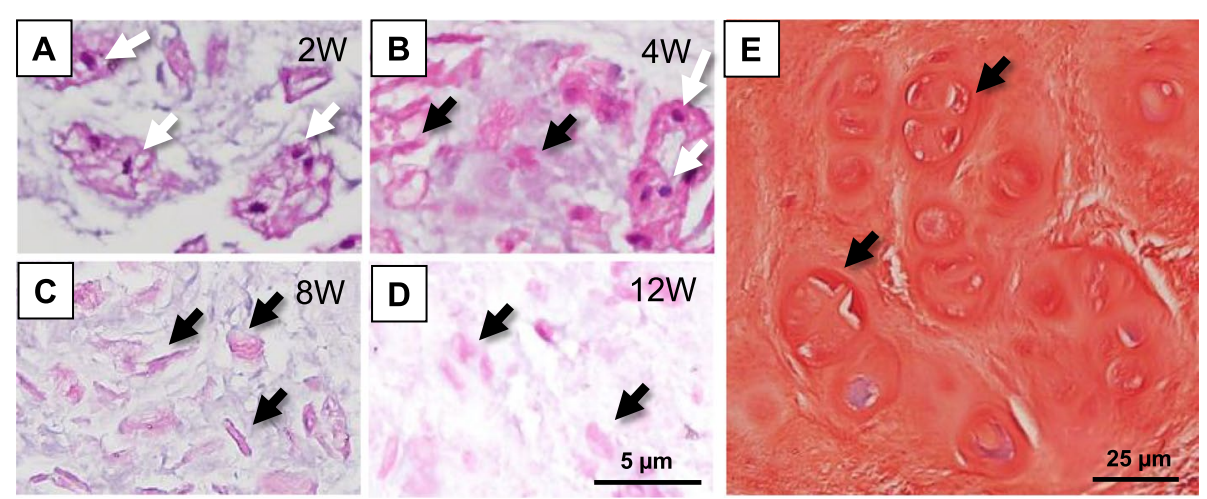

Fig. 11 Representative histology of nucleus pulposus cells. Histology of cellular changes in the nucleus pulpous (NP) of MIA 1.0 mg-injected discs after 2 (A), 4 (B), 8 (C), and 12 weeks (D) post-injection stained with hematoxylin-eosin are representatively shown. Scale bar: $5 \mu$ m (A-D). Safranin-O staining histology of cell clones in the NP of MIA $0.01 \mathrm{mg}$-injected disc is representatively shown (E). Scale bar: $25 \mu \mathrm{m}$ (E)

that the intradiscal injection of CA using a 31-gauge needle does not influence disc height change in this animal model.

The results of the radiographic evaluation showed that the intradiscal injection of MIA induced a progressive and temporal decrease of disc height. When comparing the $\% \mathrm{DH}$ among three different concentrations of MIA-injected discs, the intradiscal injection of MIA $0.01 \mathrm{mg}$ mildly decreased disc height compared to that of MIA $0.1 \mathrm{mg}$ - and $1.0 \mathrm{mg}$-injected discs, finally decreasing to approximately $80 \%$ of baseline. On the other hand, the two higher doses of MIA (0.1 and $1.0 \mathrm{mg})$ induced a final decrease in disc height to approximately $50 \%$ of baseline; however, no significant difference was found between 
the two doses. These results suggest that there would be significant differences in the effect of disc height narrowing between the administration of low-dose MIA (0.01 $\mathrm{mg})$ and high dose MIA $(0.1$ and $1.0 \mathrm{mg})$ into the rabbit IVDs, with a similar effect between MIA 0.1 and $1.0 \mathrm{mg}$. Accordingly, MIA $0.1 \mathrm{mg}$ would be a necessary and sufficient dose for the severe disc height narrowing of rabbit IVDs.

Due to the three-dimensional nature of the intervertebral structure, disc height varies depending on the area of measurement [23]. 3D quantification of disc height would be ideal and more accurate than measurement by radiography [30]. Therefore, the 3D-DHI of whole and five anatomical zones was evaluated by $3 \mathrm{D}-\mathrm{CT}$ analysis. The change in 3D-DHI following MIA injection showed a tendency similar to that of the \% $\mathrm{DHI}$ evaluated by lumbar radiography. The results of the anatomical zone analysis showed that the intradiscal injection of MIA predominantly induced disc height narrowing at the posterior AF zone. The low-dose MIA (0.01mg) mainly decreased the posterior AF zone; however, a higher dose of MIA (0.1 and $1.0 \mathrm{mg}$ ) affected not only the posterior zone but also the NP, lateral, and anterior zones. Tsuji et al. [31] conducted a microscopic observation of AF tissues of young human IVDs and showed that the number of lamellar bundles in the anterior AF was higher than that in the posterior AF. Furthermore, a high percentage of incomplete and/or discontinuous lamellar bundles was found in the posterior AF tissues, suggesting the mechanical friability of posterior human AF tissue. Similar morphological and histological characteristics were also identified in rabbit AF tissues. Therefore, the authors speculated that MIA would induce a structural failure primarily in the posterior AF tissues, which leads to non-uniform disc height narrowing depending on the disc zones.

MRI T2-mapping has been shown to quantitatively evaluate changes in water and proteoglycan (PG) content and arrangement of the collagen network structure of human IVDs [32, 33]. Notably, previous studies have shown that $\mathrm{T} 2$ values in human IVDs have a significant correlation with the degree of disc degeneration [10, 33, 34]. Our results of MRI T2 mapping showed that the intradiscal injection of MIA significantly affected changes in MRI T2 values of rabbit IVDs. MIA induced a dose-dependent decrease in MRI T2-values at 4, 8, and 12 weeks post-injection, suggesting that MIA decreases water content and induces changes in the molecular composition of the extracellular matrix (ECM) of rabbit IVDs.

Two weeks post-injection of MIA-injected discs, histological analyses showed that the ECM in the NP lesion showed only a mild change while maintaining a fine cotton-like appearance. However, the condensational change of the ECM progressed time-dependently until 12 weeks post-injection in all doses of MIA-injected discs. These time- and dose-dependent changes of histology in the NP would be responsible for the changes in MRI T2 values. Our results also showed that MRI T2 values were strongly correlated with total histological grading scores and subclass grading scores, except for the "EP." Takahashi et al. [35] injected MIA (0.2 mg and 1.0 $\mathrm{mg}$ ) into rat knee joints and evaluated the histopathological changes in articular cartilage. They reported that substantial numbers of chondrocyte death, identified by abnormality of nuclei, were detected in both doses of MIA-injected knees and that $0.2 \mathrm{mg}$ of MIA induced a mild osteoarthritis change while $1.0 \mathrm{mg}$ of MIA induced end-stage osteoarthritic changes. Histological changes of rat articular cartilage after the injection of MIA shared features common to the histological results of our rabbit disc study.

Partial ruptures and serpentine patterns of fibers were mainly found in posterior AF tissues of MIA $0.1 \mathrm{mg}$ - and $1.0 \mathrm{mg}$-injected discs, while no remarkable histological changes were identified in anterior AF tissues. These histological findings would be attributed to the decreased disc height at the posterior AF zone as shown by 3D-DH analysis. Boos et al. [36] semi-quantitatively evaluated the age-related histological changes of human IVD tissues and reported that degenerative changes that started in the second decade of life were initially found in the NP. Cell death and chondrocyte proliferation were found in samples from children and temporally increased to adulthood. The substantial increase in cell death associated with extensive chondrocyte proliferation was found in IVDs from teenagers and was most pronounced in samples from adults 30 to 50 years old [36]. In our rabbit study, cell cloning (cluster formation) was locally detected in approximately $30-50 \%$ of the NP of discs injected with MIA (0.01 and $0.1 \mathrm{mg}$ ), but not with MIA $(1.0 \mathrm{mg})$. Hence, we recognized that the cell proliferative activity of the rabbit NP would be impaired after MIA injection; this would be different from the histopathologic changes found in human IVD degeneration.

Jiang et al. [17] examined the cytotoxic effect of MIA on rat chondrocytes in vitro and showed that MIA treatment induced apoptosis in chondrocytes by upregulating cytochrome $c$ and caspase- 3 protein levels. The results of these previous reports and our study suggest that intradiscal injection of MIA into rabbit IVDs would induce degenerative tissue changes caused by cell death in rabbit IVDs.

Suh et al. [21] reported that the intradiscal injection of MIA increased nuclear factor-kappa B (NF- $\mathrm{kB}$ ) and cyclooxygenase-2 (COX-2) expression in rat IVDs and dorsal root ganglia (DRGs); these are the chief regulators 
of catabolic factors and inflammatory pain. Therefore, we speculated that the administration of MIA might also have a catabolic effect on rabbit IVD cells and induce discogenic pain; this would be worth investigating in a future study.

Because cell death is one of the characteristics of this MIA-induced IVD degeneration model, there is the possibility that this model might be appropriate for evaluating cell replacement therapies, such as the use of mesenchymal stem cells [37] or progenitor cells [38]. While administering a high dose of MIA (0.1 or 1.0 $\mathrm{mg}$ ) resulted in an advanced stage of IVD degeneration, this could be utilized to test tissue-engineered IVDs or intervertebral implants.

There are several limitations to this study. First, we have evaluated the effect of MIA on rabbit IVD degeneration until 12 weeks; however, the long-term effects of MIA have not been evaluated. Second, it has been reported that the response of rabbit IVDs against external stimuli, such as disc puncture, differs among disc levels, probably due to differences in disc volume [39]. Therefore, the effect of MIA on rabbit IVDs might differ among L2-L3, L3-L4, and L4-L5 discs.

\section{Conclusions}

For the first time, we have shown that the intradiscal injection of MIA induced degenerative changes of rabbit IVDs evaluated by radiography, CT, MRI, and histology. The progression of disc height narrowing that was evaluated by radiography and CT and the decrease in MRI T2 values induced by MIA injection would be like those of human IVD degeneration. However, MIA induced cell death in the rabbit NP with a high percentage, while cell proliferation (cell cloning) was low; these cellular changes would differ from the pathophysiology of human IVD degeneration. Nevertheless, based on the dose-dependent degenerative changes induced by MIA, MIA injection into rabbit IVDs could be used as an animal model of IVD degeneration.

\footnotetext{
Abbreviations

AF: Annulus fibrosus; 3D-DH: Three-dimensional disc height; ECM: Extracellular matrix; IVD: Intervertebral disc; MAPK: Mitogen-activated protein kinase; MIA: Monosodium iodoacetate; $\mu \mathrm{CT}$ : Micro-computed tomography; MRI: Magnetic resonance imaging; NP: Nucleus pulposus; PG: Proteoglycan.
}

\section{Acknowledgements}

The authors acknowledge Takahiro lino and Katsura Chiba for their assistance in the preparation of tissue specimens for histological analysis.

\section{Authors' contributions}

TS performed the animal study and data acquisition and drafted the manuscript. KA helped perform the animal study and statistical analyses, drafted the manuscript, conceived of this study, and made substantial contributions to the study design. KK, TH, and JY performed data acquisition and revised the manuscript. NI programmed a custom-written software for 3D-CT analysis.
KM contributed to the study coordination and revised the manuscript. AS contributed to the study design and coordination and revised the manuscript. All authors read and approved the final manuscript.

\section{Funding}

Not applicable.

\section{Availability of data and materials}

The datasets used and/or analyzed during the current study are available from the corresponding author on reasonable request.

\section{Declarations}

Ethics approval and consent to participate

The Institutional Animal Research Committee of Mie University approved the protocol of this study (reference number: 29-14).

\section{Consent for publication}

Not applicable.

\section{Competing interests}

The authors declare that they have no competing interests.

\section{Author details}

${ }^{1}$ Department of Orthopaedic Surgery, Mie University Graduate School of Medicine, 2-174 Edobashi, Tsu City, Mie 514-8507, Japan. ${ }^{2}$ Department of Orthopedic Surgery, Rush Medical College, Chicago, IL 60612-3833, USA. ${ }^{3}$ Department of Orthopaedic Surgery, University of California, San Diego, 9500 Gilman Dr, La Jolla 92093-0863, USA.

Received: 7 October 2021 Accepted: 24 November 2021

Published online: 08 December 2021

\section{References}

1. Hartvigsen J, Hancock MJ, Kongsted A, Louw Q, Ferreira ML, Genevay S, et al. What low back pain is and why we need to pay attention. Lancet. 2018;391 (10137):2356-67.

2. Ohtori S, Miyagi M, Inoue G. Sensory nerve ingrowth, cytokines, and instability of discogenic low back pain: a review. Spine Surg Relat Res. 2018;2(1):11-7.

3. Suzuki H, Kanchiku T, Imajo Y, Yoshida Y, Nishida N, Taguchi T. Diagnosis and characters of non-specific low back pain in Japan: The Yamaguchi Low Back Pain Study. PLoS One. 2016;1 1 (8):e0160454.

4. Vo NV, Hartman RA, Patil PR, Risbud MV, Kletsas D, latridis JC, et al. Molecular mechanisms of biological aging in intervertebral discs. J Orthop Res. 2016;34(8):1289-306.

5. Urban JP, Roberts S. Degeneration of the intervertebral disc. Arthritis Res Ther. 2003;5(3):120-30.

6. Pazzaglia UE, Salisbury JR, Byers PD. Development and involution of the notochord in the human spine. J R Soc Med. 1989;82(7):413-5.

7. Zhao CQ, Wang LM, Jiang LS, Dai LY. The cell biology of intervertebral disc aging and degeneration. Ageing Res Rev. 2007;6(3):247-61.

8. Vernon-Roberts B, Moore RJ, Fraser RD. The natural history of agerelated disc degeneration: the pathology and sequelae of tears. Spine. 2007;32(25):2797-804.

9. Raudner M, Schreiner MM, Hilbert T, Kober T, Weber M, Szelenyi A, et al. Clinical implementation of accelerated T2 mapping: quantitative magnetic resonance imaging as a biomarker for annular tear and lumbar disc herniation. Eur Radiol. 2020;31:3590-9.

10. Yoon MA, Hong SJ, Kang CH, Ahn KS, Kim BH. T1 rho and T2 mapping of lumbar intervertebral disc: correlation with degeneration and morphologic changes in different disc regions. Magn Reson Imaging. 2016;34(7):932-9.

11. Murata K, Akeda K, Takegami N, Cheng K, Masuda K, Sudo A. Morphology of intervertebral disc ruptures evaluated by vacuum phenomenon using multi-detector computed tomography: association with lumbar disc degeneration and canal stenosis. BMC Musculoskelet Disord. 2018;19(1):164. 
12. Akeda K, Yamada T, Inoue N, Nishimura A, Sudo A. Risk factors for lumbar intervertebral disc height narrowing: a population-based longitudinal study in the elderly. BMC Musculoskelet Disord. 2015;16:344.

13. Videman T, Saarela J, Kaprio J, Nakki A, Levalahti E, Gill K, et al. Associations of 25 structural, degradative, and inflammatory candidate genes with lumbar disc desiccation, bulging, and height narrowing. Arthritis Rheum. 2009;60(2):470-81.

14. Daly C, Ghosh P, Jenkin G, Oehme D, Goldschlager T. A review of animal models of intervertebral disc degeneration: pathophysiology, regeneration, and translation to the clinic. Biomed Res Int. 2016;2016:5952165.

15. Kuyinu EL, Narayanan G, Nair LS, Laurencin CT. Animal models of osteoarthritis: classification, update, and measurement of outcomes. J Orthop Surg Res. 2016;11:19.

16. Grossin L, Cournil-Henrionnet C, Pinzano A, Gaborit N, Dumas D, Etienne S, et al. Gene transfer with HSP 70 in rat chondrocytes confers cytoprotection in vitro and during experimental osteoarthritis. FASEB J. 2006;20(1):65-75.

17. Jiang L, Li L, Geng C, Gong D, Jiang L, Ishikawa N, et al. Monosodium iodoacetate induces apoptosis via the mitochondrial pathway involving ROS production and caspase activation in rat chondrocytes in vitro. J Orthop Res. 2013;31(3):364-9.

18. Guingamp C, Gegout-Pottie P, Philippe L, Terlain B, Netter P, Gillet P. Mono-iodoacetate-induced experimental osteoarthritis: a dose-response study of loss of mobility, morphology, and biochemistry. Arthritis Rheum. 1997;40(9):1670-9.

19. Guzman RE, Evans MG, Bove S, Morenko B, Kilgore K. Mono-iodoacetateinduced histologic changes in subchondral bone and articular cartilage of rat femorotibial joints: an animal model of osteoarthritis. Toxicol Pathol. 2003;31(6):619-24.

20. Udo M, Muneta T, Tsuji K, Ozeki N, Nakagawa Y, Ohara T, et al. Monoiodoacetic acid induces arthritis and synovitis in rats in a dose- and time-dependent manner: proposed model-specific scoring systems. Osteoarthr Cartil. 2016;24(7):1284-91.

21. Suh HR, Cho HY, Han HC. Development of a novel model of intervertebral disc degeneration by the intradiscal application of monosodium iodoacetate (MIA) in rat. Spine J. 2021. https://doi.org/10.1016/j.spinee.2021.06 008.

22. Masuda K, Imai Y, Okuma M, Muehleman C, Nakagawa K, Akeda K, et al. Osteogenic protein-1 injection into a degenerated disc induces the restoration of disc height and structural changes in the rabbit anular puncture model. Spine. 2006;31(7):742-54.

23. Espinoza Orias AA, Mammoser NM, Triano JJ, An HS, Andersson GB, Inoue N. Effects of axial torsion on disc height distribution: an in vivo study. J Manip Physiol Ther. 2016;39(4):294-303.

24. Watanabe S, Inoue N, Yamaguchi T, Hirano Y, Espinoza Orias AA, Nishida $\mathrm{S}$, et al. Three-dimensional kinematic analysis of the cervical spine after anterior cervical decompression and fusion at an adjacent level: a preliminary report. Eur Spine J. 2012;21(5):946-55.

25. Imanishi T, Akeda K, Murata K, Sudo A. Effect of diminished flow in rabbit lumbar arteries on intervertebral disc matrix changes using MRI T2-mapping and histology. BMC Musculoskelet Disord. 2019;20(1):347.

26. Chujo T, An HS, Akeda K, Miyamoto K, Muehleman C, Attawia M, et al. Effects of growth differentiation factor-5 on the intervertebral disc--in vitro bovine study and in vivo rabbit disc degeneration model study. Spine. 2006:31(25):2909-17.

27. Gullbrand SE, Ashinsky BG, Lai A, Gansau J, Crowley J, Cunha C, et al. Development of a standardized histopathology scoring system for intervertebral disc degeneration and regeneration in rabbit models-an initiative of the ORSspine section. JOR Spine. 2021;4(2):e1147.

28. Masuda K, Aota Y, Muehleman C, Imai Y, Okuma M, Thonar EJ, et al. A novel rabbit model of mild, reproducible disc degeneration by an anulus needle puncture: correlation between the degree of disc injury and radiological and histological appearances of disc degeneration. Spine. 2005;30(1):5-14.

29. Janke $L$, Ward JM, Vogel P. Classification, scoring, and quantification of cell death in tissue sections. Vet Pathol. 2019:56(1):33-8.

30. Akeda K, Cheng K, Abarado E, Takegami N, Yamada J, Inoue N, et al. Three-dimensional computed tomographic evaluation of lateral lumbar interbody fusion: morphometric change of intervertebral structure. Eur Spine J. 2021;30(5):1355-64
31. Tsuji H, Hirano N, Ohshima H, Ishihara H, Terahata N, Motoe T. Structural variation of the anterior and posterior anulus fibrosus in the development of human lumbar intervertebral disc. A risk factor for intervertebral disc rupture. Spine. 1993;18(2):204-10.

32. Antoniou J, Pike GB, Steffen T, Baramki H, Poole AR, Aebi M, et al. Quantitative magnetic resonance imaging in the assessment of degenerative disc disease. Magn Reson Med. 1998;40(6):900-7.

33. Marinelli NL, Haughton VM, Anderson PA. T2 relaxation times correlated with stage of lumbar intervertebral disk degeneration and patient age. AJNR Am J Neuroradiol. 2010;31(7):1278-82.

34. Watanabe A, Benneker LM, Boesch C, Watanabe T, Obata T, Anderson SE. Classification of intervertebral disk degeneration with axial T2 mapping. AJR Am J Roentgenol. 2007;189(4):936-42.

35. Takahashi I, Matsuzaki T, Kuroki H, Hoso M. Induction of osteoarthritis by injecting monosodium iodoacetate into the patellofemoral joint of an experimental rat model. PLoS One. 2018;13(4):e0196625.

36. Boos N, Weissbach S, Rohrbach H, Weiler C, Spratt KF, Nerlich AG. Classification of age-related changes in lumbar intervertebral discs: 2002 Volvo Award in basic science. Spine. 2002;27(23):2631-44.

37. Schol J, Sakai D. Cell therapy for intervertebral disc herniation and degenerative disc disease: clinical trials. Int Orthop. 2019;43(4):1011-25.

38. Sakai D, Nakamura Y, Nakai T, Mishima T, Kato S, Grad S, et al. Exhaustion of nucleus pulposus progenitor cells with ageing and degeneration of the intervertebral disc. Nat Commun. 2012;3:1264.

39. Martin JT, Collins CM, Ikuta K, Mauck RL, Elliott DM, Zhang Y, et al. Population average T2 MRI maps reveal quantitative regional transformations in the degenerating rabbit intervertebral disc that vary by lumbar level. J Orthop Res. 2015;33(1):140-8.

\section{Publisher's Note}

Springer Nature remains neutral with regard to jurisdictional claims in published maps and institutional affiliations.

Ready to submit your research? Choose BMC and benefit from

- fast, convenient online submission

- thorough peer review by experienced researchers in your field

- rapid publication on acceptance

- support for research data, including large and complex data types

- gold Open Access which fosters wider collaboration and increased citations

- maximum visibility for your research: over $100 \mathrm{M}$ website views per year

At BMC, research is always in progress.

Learn more biomedcentral.com/submissions 